\title{
The Canadian Opioid Crisis: CSHP's Commitment
}

\author{
Patrick Fitch
}

$\mathrm{T}$ here is no escaping the headlines. Canada is in the midst of an opioid crisis. More than 2900 apparent opioid-related deaths occurred in 2016 and nearly 3000 in the first 9 months of 2017 (https:/www.canada.ca/en/health-canada/services/substanceabuse/prescription-drug-abuse/opioids/apparent-opioid-relateddeaths.html). Canada has one of the highest rates of opioid use in the world (according to the International Narcotics Control Board; https://www.incb.org/incb/en/narcotic-drugs/Availability/ availability.html). This public health issue requires action from multiple stakeholders.

The Canadian Society of Hospital Pharmacists (CSHP) participated in opioid conferences hosted by the Government of Canada (November 2016) and the Canadian Pharmacists Association (June 2017), and committed to a number of actions to help resolve the crisis (https://cshp.ca/opioid-crisis). Here are progress reports on several of them.

CSHP surveyed members about their needs for resources on prevention, education, treatment, monitoring, and surveillance, as well as enforcement practices concerning controlled substances. Analysis of the results is underway. Expect the full results shortly.

CSHP is advocating for the designation of pharmacists under the New Classes of Practitioners Regulations. In provinces that already allow pharmacist prescribing, this designation would extend prescribing authorization to controlled substances.

CSHP is leading the development of guidelines for preventing, identifying, and responding to diversion of controlled substances in hospitals and other healthcare organizations. Our core partners include Health Canada, HealthCare $C A N$, the Canadian Nurses Association, and the Canadian Anesthesiologists' Society. Other groups serving as contributors or expert consultants include the Institute for Safe Medication Practices Canada, the Paramedic Association of Canada, the Canadian Association of Emergency Physicians, health professional regulatory bodies, and researchers in the field. We are reaching out to important stakeholders in long-term care, hospital accreditation, and law enforcement. The final guidelines, which will incorporate the best available evidence, should be ready for publication in December.
We are gathering and posting educational and practice-related resources on opioid use in the Pharmacy 365 section of our website (https://cshp.ca/ pain-management).

We as individual pharmacy practitioners must also play our part. Canada's high rate of opioid use suggests the need for a

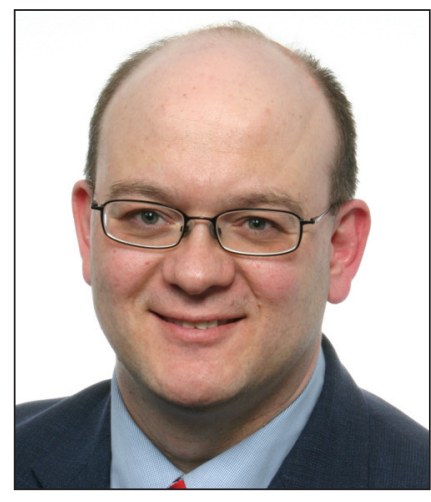
paradigm or cultural shift in how we treat acute pain and chronic noncancer pain. The public is taking note as well. Recently, a Globe and Mail columnist highlighted a study looking at the unintended consequences of widespread naloxone availability (see https:// www.theglobeandmail.com/opinion/article-does-naloxonereally-save-lives/ and https://ssrn.com/abstract=3135264). For example, as drug users realize they are less likely to die from an overdose through the availability of naloxone, they may start to use more often, use higher doses, or switch to more powerful drugs. Drug-related theft has increased, as have emergency department visits.

During the 2018 CSHP Professional Practice Conference, I heard the term "opioid stewardship" several times. Speakers suggested that pharmacists can act in many ways to promote rational use of opioids, including provision of alternative pain control strategies when appropriate. For example, opioids are often not the best choice for chronic noncancer pain.

Just as pharmacists have taken on the mantle of antibiotic stewardship, I challenge all CSHP members to adopt opioid stewardship as a core element of their practice.

Patrick Fitch, BSP, ACPR, is President and Internal Liaison for the Canadian Society of Hospital Pharmacists. 